\title{
Longitudinal study of energy and nutrient intakes for infants from low-income, urban families
}

\author{
Karen Nolan ${ }^{1, *}$, Lawrence M Schell ${ }^{2}$, Alice D Stark and Marta I Gómez ${ }^{1}$ \\ 'Bureau of Environmental and Occupational Epidemiology, New York State Department of Health, 547 River Street, \\ Room 200, Troy, NY 12180-2216, USA: ²Department of Epidemiology, University at Albany, State University of \\ New York, Albany, NY, USA
}

Submitted 16 February 2001: Accepted 1 0ctober 2001

\begin{abstract}
Objective: To assess the energy and nutrient intakes of healthy infants from lowincome families and to compare intakes with current recommendations.

Design: We interviewed mother-infant pairs longitudinally when the infants were 3 , 6, 9, 12, 18 and 24 months old. Food intake data were obtained by 24-hour dietary recalls. Selected nutrient intakes were calculated and compared with the Recommended Dietary Allowances (RDAs).

Subjects/setting: Infants $(n=200)$ were the offspring of low-income, pregnant women recruited at the Albany County Department of Health, New York for the Albany Pregnancy and Infancy Lead Study, a prospective investigation of factors related to blood lead levels, including nutrition. Interviews were conducted during paediatric clinic visits.

Statistical analyses performed: Means and standard deviations were used to describe energy and micronutrient intakes for age groups. The probability approach was utilised to examine the prevalence of inadequate intakes.

Results: Mean energy and nutrient intakes generally met or exceeded the RDA. The exceptions were vitamin D and zinc for which observed means were below the RDA at several data points. Protein consumption was exceptionally high in this sample. The highest estimated prevalences of inadequate intakes were observed for iron, zinc and vitamin $\mathrm{D}$ at the older ages.

Conclusions: This study identified several potential concerns about the diets of infants during the transition from infant food and formula to table foods. Low intakes of vitamin D, zinc and iron, especially at 12 and 18 months, were observed. High protein intakes were noted at all ages.
\end{abstract}

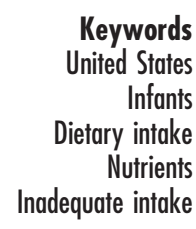

Limited information is available on changes in the nutritional adequacy of infant diets in the United States. Large-scale national surveys provide some description of intakes at specific ages, but are based on cross-sectional data $^{1-5}$. Longitudinal investigations of changes in dietary intake among healthy American infants are rare. Several studies have described changes in diet composition or have chronicled the introduction of specific foods, such as cow's milk or table foods, but have not provided information about changes in the intake of key nutrients ${ }^{6-9}$. Studies assessing vitamin and mineral intakes have focused on preschool or older children rather than infants ${ }^{10-13}$. One recent investigation examined food and nutrient intakes of infants from middle to upper class families ${ }^{14}$.

This longitudinal investigation of nutrient intakes is part of a larger investigation undertaken by the University at Albany, State University of New York and the New York
State Department of Health to examine the blood lead levels of poor, pregnant women and their children, and to determine the relationship of these lead levels to other factors including nutrition. We analysed the dietary intakes of energy and five nutrients (protein, calcium, iron, zinc and vitamin D) in a group of infants 3 to 24 months of age from low-income, urban families. These particular nutrients were chosen for study because recommended dietary intakes were readily available and because diets low in minerals such as iron, calcium and zinc favour the absorption and storage of lead in the body ${ }^{15}$. We compared energy and nutrient intakes with US recommended daily allowance values set forth by the National Research Council ${ }^{16}$. This report describes dietary intakes during a critical period of transition from formula to table food during which significant growth and development take place. 


\section{Methods}

\section{Recruitment}

The data were collected as part of Phase I of the Albany Pregnancy/Infancy Lead Study - a prospective cohort study of lead levels during pregnancy and their relationship to the offspring's lead levels, postnatal growth and development. Pregnant women were recruited for the study during prenatal obstetrical visits at the Albany County Department of Health (ACDOH) in Albany, New York. The women consented to participate in the study throughout their pregnancies, as well as having their infants followed through two years of age. Infant followup was conducted between December 1986 and September 1993. Additional details of the study including recruitment procedures and eligibility criteria have been published elsewhere ${ }^{17,18}$.

\section{Interviews}

We obtained information on dietary intake from interviews conducted with the mothers during regularly scheduled paediatric visits for their infants at the ACDOH. These paediatric appointments were scheduled on weekdays throughout the year. The interviews were conducted when the infants were 3, 6, 9, 12, 18 and 24 months old. Study visits took place within an eight-week window based on the infant's age (e.g. 3 months \pm 4 weeks). All interviews were conducted by one of two registered nurses who were trained in proper interviewing techniques.

At each visit, the infant's mother or primary caregiver was asked to complete a 24-hour dietary recall of the infant's food intake during the previous day, including formula, breast milk, infant food, table food and vitamin/ mineral supplements. Food models and standard measuring cups were used to assist the mothers in recalling portion sizes. Brand names were elicited whenever possible. If the infant was breast-fed, the mother was asked to report the frequency and duration of nursing. Anthropometric measurements including weight and length were also recorded at each visit.

\section{Sample}

The sample was drawn from infants born at Albany Medical Center in Albany, New York to mothers participating in Phase I of the Albany Pregnancy/Infancy Lead Study. In order to participate in the study the women had to be Albany County residents and eligible for the Women, Infants and Children (WIC) food supplement programme. The sample was drawn from a low-income, largely urban population.

In total, 316 pregnant women were enrolled in Phase I. Ninety-three of these women did not remain in the study to delivery because they moved out of the area or otherwise became lost to follow-up $(n=65)$, terminated their pregnancy $(n=24)$ or expressed a desire to discontinue participation $(n=4)$. Of the 223 infants born to participating women, 20 infants never completed a study visit because the mother decided to discontinue her participation $(n=10)$, the mother-infant pair moved out of the area or could not be located $(n=9)$, and in one case the infant died. Additionally, three infants were excluded from the sample because they were exclusively breast-fed at three months of age and subsequently dropped out of the study; therefore, no food intake information was collected for these infants. This resulted in a sample of 200 infants for which at least one paediatric visit was conducted and dietary intake information was collected. Of the 200 mother-infant pairs enrolled, 147 (74\%) completed the 24-month study with at least three interviews. The remainder moved out of the area or could not be located ( $n=32$ ) or chose to discontinue their participation $(n=21)$.

\section{Data analysis}

The 200 infants in the sample contributed a total of 920 dietary recalls. Nineteen mothers (9.5\%) reported breastfeeding their infants, either completely or partially, at one or more visits. Completely breast-fed infants were given no infant foods or formulas and partially breast-fed infants were given infant foods and/or formula in addition to breast milk. These infants contributed 33 dietary recalls that were not comparable to the diets of non-breast-fed infants because they contained little or no food intake information. Therefore, these diets were excluded from this analysis. The remaining 887 dietary recalls were systematically coded for nutrient analysis by one of the authors (KN) using Nutritionist IV software ${ }^{19}$. Nutrient values generated by the Nutritionist IV food database, along with information on breast-feeding frequency and duration, were managed in Visual dBase ${ }^{20}$. The Statistical Analysis System ${ }^{21}$ was used for statistical analysis.

Mean energy and nutrient intakes were calculated for each visit and compared with age-appropriate 1989 Recommended Dietary Allowances (RDAs) ${ }^{16}$. RDA standards were chosen for each study visit based on the age distribution of the infants at each visit. Intakes at 3 and 6 months were compared with the RDA for infants 0 to 0.5 years old. Intakes at 9 months were compared with the RDA for infants 0.5 to 1 year old. Intakes at 12,18 and 24 months were compared with the RDA for children 1 to 3 years old.

To estimate the prevalence of inadequate intake of protein, calcium, iron, zinc and vitamin $\mathrm{D}$ at each study visit in this sample of infants, we used the probability approach as described by the National Research Coun$\mathrm{cil}^{22,23}$. This method compares each infant's nutrient intake to the distribution of the age-specific intake requirement for that nutrient. The requirement distribution is assumed to be normally distributed with mean and standard deviation (SD) derived from the RDA (mean $+2 \mathrm{SD})$ and a coefficient of variation of 0.15 . This coefficient of variation 
is based on data published in the 1989 RDA. Each infant is assigned a risk of inadequate intake $\left(r_{\mathrm{i}}\right)$ based on the requirement distribution and is the area under the normal curve to the right of an infant's observed intake. That is, the lower the infant's intake, the greater the probability that it is inadequate compared with the requirement distribution. The infant's risk is then weighted by the probability of observing that level of intake at the study visit in the study sample $\left(p_{\mathrm{i}}\right)$, where the distribution is assumed to be normally distributed. The weights are normalised by dividing each $p_{\mathrm{i}}$ by the sum of the $p_{\mathrm{i}}$ s (i.e. $p_{\mathrm{i}} / \Sigma p_{\mathrm{i}}$ ). Finally, the prevalence of inadequate intake for a given nutrient at a study visit is the weighted average of the risk of inadequate intake $\Sigma r_{\mathrm{i}}\left(p_{\mathrm{i}} / \Sigma p_{\mathrm{i}}\right)$, summed over the number of infants with intake data at that study visit.

\section{Results}

\section{Subjects' characteristics}

More than half (51\%) of the mothers in this study had not completed high school. Mean age of the mothers was 22 years, with a vast majority (93\%) of the women being in their teens and twenties upon enrolment. Fifty-six per cent of the mothers were black and $41 \%$ were white. The remaining $4 \%$ reported Hispanic ethnicity. Nearly threequarters $(73 \%)$ of the women were unmarried.

Of the 200 infants having at least one study visit, 147 infants remained in the study through completion and 53 infants dropped out before reaching their second birthday. Maternal characteristics of these two groups were compared to determine if mothers who chose to complete the study differed in age, educational attainment, race or marital status from those who dropped out of the study. No significant differences were found $(P<0.05)$. Table 1 shows the maternal characteristics for these two groups and the full sample.

\section{Antbropometrics}

Information on the anthropometric status of the infants is presented in Table 2. At most ages, males were lighter and shorter than United States' growth standards ${ }^{24}$ as indicated by negative $Z$-scores for weight and length (i.e. below the 50 th percentile). This was also true for female infants at 6 and 9 months. At all other ages, the stature of the females generally exceeded the US reference with weight and length $Z$-scores above the 50 th percentile. In general, the male study infants are on average shorter and lighter than the reference population while the female study infants are longer and heavier than the reference population.

\section{Energy and nutrient intakes}

Mean energy and nutrient intakes for the infants are presented in Table 3. The average intake for energy and nutrients met or exceeded age-appropriate RDAs at nearly every age, with two notable exceptions. First, mean zinc intake did not meet the RDA at the 12- and 18-month visits. The lowest intake was observed at the 12-month visit when infants achieved a mean intake of just $67 \%$ of the RDA for zinc. Second, mean vitamin D intake was lower than the RDA at the 9-, 12-, 18- and 24-month visits. At 9 months, the infants were consuming, on average, $94 \%$ of the RDA for vitamin D. By the last study visit, mean vitamin D intake was less than $75 \%$ of the vitamin D RDA for 2 year olds. High protein consumption was prevalent among these infants; mean protein intake exceeded the RDA at all visits. At 9 months of age, infants were consuming more than twice the RDA for protein and at 24 months the average protein intake was nearly four times the RDA.

Table 1 Selected maternal characteristics

\begin{tabular}{lccc}
\hline & $\begin{array}{c}\text { Full sample } \\
(n=200)\end{array}$ & $\begin{array}{c}\text { Completed study } \\
(n=147)\end{array}$ & $\begin{array}{c}\text { Dropped-out* } \\
(n=53)\end{array}$ \\
\hline Age (years) & & & \\
Mean & 21.6 & 21.7 & 21.4 \\
Median & 20.7 & 20.7 & 20.5 \\
$\quad$ Range & $13-41$ & $13-39$ & $16-41$ \\
Education† (\%) & & & \\
7th-9th grade & 12.8 & 12.4 & 13.7 \\
10th-11th grade & 38.3 & 37.9 & 39.2 \\
High school graduate & 39.8 & 40.7 & 37.3 \\
Some college & 8.7 & 8.3 & 9.8 \\
College graduate & 0.5 & 0.7 & 0.0 \\
Race (\%) & & & 45.3 \\
White & 40.5 & 38.8 & 52.8 \\
Black & 55.5 & 56.5 & 1.9 \\
$\quad$ Hispanic & 4.0 & 4.8 & 69.8 \\
Marital status (\%) & & & 24.5 \\
Single & 73.0 & 74.2 & 3.8 \\
Married & 21.0 & 19.7 & 1.9 \\
$\quad$ Separated & 5.5 & 6.1 & 0.0 \\
$\quad$ Divorced & 0.5 & & \\
\hline
\end{tabular}

* No significant differences (at $P<0.05$ ) in maternal characteristics between infants who remained in the study and those who dropped out of the study. †Education level was missing for four participants. 
Table 2 Infant anthropometrics at 3, 6, 9, 12, 18 and 24 months

\begin{tabular}{lcccccc}
\hline & 3 months & 6 months & 9 months & 12 months & 18 months & 24 months \\
\hline Males & $(n=91)$ & $(n=94)$ & $(n=95)$ & $(n=83)$ & $(n=78)$ & $(n=69)$ \\
Weight $(\mathrm{kg})$ & $5.94 \pm 1.08$ & $8.04 \pm 0.96$ & $9.29 \pm 1.14$ & $10.24 \pm 1.21$ & $11.84 \pm 1.43$ & $12.93 \pm 1.54$ \\
Length $(\mathrm{cm})$ & $59.11 \pm 3.36$ & $67.25 \pm 2.73$ & $72.03 \pm 2.58$ & $76.00 \pm 2.68$ & $82.23 \pm 3.17$ & $86.90 \pm 2.90$ \\
Z-scores & & & & & \\
$\quad$ Weight-for-age & $0.33 \pm 1.45$ & $-0.19 \pm 1.04$ & $-0.25 \pm 1.08$ & $-0.27 \pm 1.10$ & $-0.05 \pm 1.11$ & $0.06 \pm 1.06$ \\
$\quad$ Length-for-age & $-0.28 \pm 1.41$ & $-0.29 \pm 1.06$ & $-0.15 \pm 0.92$ & $-0.07 \pm 0.90$ & $-0.07 \pm 0.98$ & $-0.21 \pm 0.82$ \\
$\quad$ Weight-for-length & $0.30 \pm 1.43$ & $0.28 \pm 1.17$ & $0.35 \pm 1.21$ & $0.35 \pm 1.12$ & $0.47 \pm 1.28$ & $0.43 \pm 1.18$ \\
Females & $(n=73)$ & $(n=75)$ & $(n=68)$ & $(n=66)$ & $(n=51)$ & $(n=42)$ \\
Weight (kg) & $5.73 \pm 0.98$ & $7.51 \pm 1.14$ & $7.51 \pm 1.14$ & $9.89 \pm 1.37$ & $11.51 \pm 1.78$ & $13.09 \pm 2.30$ \\
Length (cm) & $58.76 \pm 3.14$ & $65.93 \pm 2.81$ & $70.20 \pm 3.02$ & $74.72 \pm 2.78$ & $81.15 \pm 3.49$ & $86.43 \pm 3.59$ \\
Z-scores & & & & & & \\
$\quad$ Weight-for-age & $0.74 \pm 1.47$ & $0.00 \pm 1.33$ & $-0.09 \pm 1.28$ & $0.12 \pm 1.22$ & $0.20 \pm 1.33$ & $0.47 \pm 1.44$ \\
$\quad$ Length-for-age & $0.26 \pm 1.30$ & $-0.06 \pm 1.06$ & $-0.13 \pm 1.08$ & $0.12 \pm 0.95$ & $0.12 \pm 1.08$ & $0.07 \pm 1.02$ \\
$\quad$ Weight-for-length & $0.24 \pm 1.39$ & $0.10 \pm 1.31$ & $0.28 \pm 1.20$ & $0.41 \pm 1.22$ & $0.50 \pm 1.43$ & $0.62 \pm 1.61$ \\
\hline
\end{tabular}

In data not shown, very few gender differences in nutrient intakes were observed. In all cases, male infants had significantly greater intakes than females (at $P<0.05$ ). Although male infants appeared to consume significantly more kilocalories than females at 6 months of age $(830 \mathrm{kcal}$ vs. $758 \mathrm{kcal})$, this difference ceased to exist when the infants' weight was taken into account (approximately $103 \mathrm{kcal} \mathrm{kg}^{-1}$ for males and females). At both 6 and 9 months, males had an average iron intake of $14 \mathrm{mg}$ while the mean intake for female infants was $11 \mathrm{mg}$.

Table 3 Mean intakes and supplement use at 3, 6, 9, 12, 18 and 24 months

\begin{tabular}{|c|c|c|c|c|}
\hline \multirow[b]{2}{*}{ Energy and nutrient } & \multirow[b]{2}{*}{$\mathrm{RDA}^{\mathrm{a}}$} & \multicolumn{2}{|c|}{ Month of interview } & \\
\hline & & $3(n=164)$ & $6(n=170)$ & \\
\hline Energy (kcal) & 650 & $700 \pm 233^{*}$ & $798 \pm 214 \dagger$ & \\
\hline Energy $\left(\mathrm{kcal} \mathrm{kg}^{-1}\right)$ & 108 & $121.9 \pm 48.4$ & $103.2 \pm 27.3$ & \\
\hline Protein $(\mathrm{g})$ & 13 & $16 \pm 7$ & $21 \pm 9$ & \\
\hline Calcium (mg) & 400 & $575 \pm 274$ & $623 \pm 250$ & \\
\hline Iron (mg) & 6 & $10.9 \pm 8.1$ & $12.8 \pm 7.1 \dagger$ & \\
\hline Zinc (mg) & 5 & $5.1 \pm 1.7$ & $5.3 \pm 1.6$ & \\
\hline Vitamin D $(\mu \mathrm{g})$ & 7.5 & $10.1 \pm 3.4$ & $9.4 \pm 2.9$ & \\
\hline \multirow[t]{2}{*}{ Supplement use (\%) } & & 17.7 & 25.3 & \\
\hline & & Month of interview & & \\
\hline Energy and nutrient & $\mathrm{RDA}^{\mathrm{b}}$ & $9(n=163)$ & & \\
\hline Energy (kcal) & 850 & $1001 \pm 286$ & & \\
\hline Energy $\left(\mathrm{kcal} \mathrm{kg}^{-1}\right)$ & 98 & $112.2 \pm 33.3$ & & \\
\hline Protein $(\mathrm{g})$ & 14 & $33 \pm 17$ & & \\
\hline Calcium (mg) & 600 & $757 \pm 420$ & & \\
\hline Iron (mg) & 10 & $12.7 \pm 9.6 \dagger$ & & \\
\hline Zinc $(\mathrm{mg})$ & 5 & $6.0 \pm 2.3$ & & \\
\hline Vitamin D $(\mu \mathrm{g})$ & 10 & $9.4 \pm 3.3$ & & \\
\hline \multirow[t]{2}{*}{ Supplement use (\%) } & & 28.8 & & \\
\hline & & \multicolumn{3}{|c|}{ Month of interview } \\
\hline Energy and nutrient & $\mathrm{RDA}^{\mathrm{c}}$ & $12(n=149)$ & $18(n=130)$ & $24(n=111)$ \\
\hline Energy (kcal) & 1300 & $1236 \pm 354$ & $1336 \pm 397$ & $1466 \pm 412$ \\
\hline Energy $\left(\mathrm{kcal} \mathrm{kg}^{-1}\right)$ & 102 & $124.6 \pm 39.4$ & $116.2 \pm 38.0$ & $114.7 \pm 33.8$ \\
\hline Protein $(\mathrm{g})$ & 16 & $50 \pm 18$ & $58 \pm 19$ & $61 \pm 19$ \\
\hline Calcium (mg) & 800 & $885 \pm 351$ & $884 \pm 411$ & $894 \pm 391 \dagger$ \\
\hline Iron (mg) & 10 & $10.6 \pm 7.8$ & $9.8 \pm 7.5$ & $14.3 \pm 13.7$ \\
\hline Zinc (mg) & 10 & $6.7 \pm 2.2$ & $7.2 \pm 3.6 \dagger$ & $9.4 \pm 7.2$ \\
\hline Vitamin D $(\mu \mathrm{g})$ & 10 & $8.4 \pm 3.1$ & $6.9 \pm 3.5$ & $7.1 \pm 3.4$ \\
\hline Supplement use (\%) & & 32.2 & 37.7 & 39.6 \\
\hline
\end{tabular}

${ }^{a}$ Recommended Dietary Allowance (RDA) for infants 0 to 0.5 years old.

${ }^{\mathrm{b}}$ Recommended Dietary Allowance (RDA) for infants 0.5 to 1 year old.

${ }^{c}$ Recommended Dietary Allowance (RDA) for infants 1 to 3 years old.

* Mean \pm standard deviation from 24-hour recalls; values in boldface are significantly less than the RDA $(P<0.05)$.

† Male intake significantly higher than female intake. 
At 18 months, on average, male infants consumed $7.7 \mathrm{mg}$ of zinc while female infants consumed $6.5 \mathrm{mg}$. Lastly, males had a mean calcium intake of $950 \mathrm{mg}$ at 24 months while the mean intake for females was $802 \mathrm{mg}$.

\section{Vitamin and mineral supplementation}

Initially, the sample was subdivided to evaluate the adequacy of the diets for those infants receiving vitamin and mineral supplements versus those who did not. There were essentially no differences in the food intake of energy and nutrients between the supplemented and nonsupplemented groups. Therefore, we chose to evaluate the dietary intake of the group as a whole regardless of supplementation. Table 3 shows the percentage of infants with reported supplement use for each visit. Supplementation status was based solely on self-report of the mother or primary caretaker. Although the majority of infants in this study did not receive any vitamin supplementation, the percentage of supplemented infants increased at each subsequent visit. At the 3-month interview 18\% of infants (17\% of males, 19\% of females) were receiving supplements and by the last study visit $40 \%$ of the infants ( $42 \%$ of males, $36 \%$ of females) were receiving supplements.

\section{Inadequate intake}

The estimated prevalences of inadequate intakes of protein, calcium, iron, zinc and vitamin $\mathrm{D}$ at each study visit are presented in Table 4 . In general, the prevalence of inadequate intake was lower at 3 and 6 months for most nutrients. The lowest prevalence of inadequacy (less than $1 \%$ ) was observed for protein from 9 to 24 months. The highest prevalence of inadequacy was observed for zinc and vitamin D, particularly at 12, 18 and 24 months. At 12 and 18 months, more than two-thirds of the sample had inadequate intake of zinc. The prevalence of inadequate vitamin D intake increased with age. The sharpest increase occurred between 12 and 18 months, when the prevalence estimate increased from 38\% to 61\%. Moderate prevalences of inadequacy were observed for calcium and iron. The prevalence of inadequate intake for iron reached $46 \%$ at 12 months and dropped to $25 \%$ at 24 months. The prevalence of inadequate intake for calcium ranged from $17 \%$ to $22 \%$ from 9 to 24 months.

Estimated prevalences of inadequate intake were also calculated separately for males and females when significant gender differences had been observed in mean usual intakes. These prevalence estimates are presented in the footnotes of Table 4. The largest discrepancy in the estimated prevalence of inadequacy between the two genders was observed for iron at 9 months, where females had an estimated prevalence of inadequacy more than twice that of males (30\% vs. 14\%, respectively).

\section{Discussion}

In addition to examining mean intakes relative to RDAs, our analysis included estimates of the prevalence of inadequate intake using the probability approach. The proportion of individuals consuming less than two-thirds of the RDA can be interpreted as a crude estimate of the prevalence of inadequate intakes ${ }^{25}$. Therefore, we can compare our prevalence estimates with the findings from other studies that did not use the probability approach.

While these children's diets can generally be described as nutritionally adequate in early infancy, this study identified a number of potential concerns later in infancy. The prevalence of inadequate intake of vitamin D was low at 3 and 6 months $(<5 \%)$, but the prevalence increased as the infants grew older. By 24 months, $61 \%$ of the sample was at risk for inadequate dietary intake of vitamin D. Because vitamin D is essential for the proper formation of the skeleton and for mineral homeostasis ${ }^{16}$, it is a critical nutrient in the diets of infants and toddlers. Skinner et al. reported dietary vitamin D deficits as early as 2 months of age $^{14}$. Their finding could have been due to the inclusion of breast-fed infants in their sample. Human milk, unlike infant formula, is not rich in vitamin D. Calculations based on reference infants and the data of Fomon ${ }^{26}$ indicate that daily intakes of vitamin D from formula are $6.75 \mu \mathrm{g}$ of cholecalciferol (vitamin $\mathrm{D}_{3}$ ) for the infant from birth to 3 months of age and $8.5 \mu \mathrm{g}$ of cholecalciferol at 4 to 6

Table 4 Estimated prevalence (\%) of inadequate nutrient intakes at 3, 6, 9, 12,18 and 24 months

\begin{tabular}{lcccccc}
\hline Nutrient & $\begin{array}{c}3 \text { months } \\
(n=164)\end{array}$ & $\begin{array}{c}6 \text { months } \\
(n=170)\end{array}$ & $\begin{array}{c}9 \text { months } \\
(n=163)\end{array}$ & $\begin{array}{c}12 \text { months } \\
(n=149)\end{array}$ & $\begin{array}{c}18 \text { months } \\
(n=130)\end{array}$ & $\begin{array}{c}24 \text { months } \\
(n=111)\end{array}$ \\
\hline Protein & 10.0 & 2.8 & 0.8 & 0.2 & 0.0 & 0.0 \\
Calcium & 5.4 & 1.9 & 21.2 & 16.5 & 22.3 & $18.5 \S$ \\
Iron & 16.8 & $8.6^{*}$ & $20.1 \dagger$ & 45.9 & 42.2 & 24.9 \\
Zinc & 19.1 & 11.9 & 10.5 & 72.2 & $67.0 \ddagger$ & 53.8 \\
Vitamin D & 3.1 & 4.4 & 29.7 & 37.7 & 60.5 & 61.3 \\
\hline
\end{tabular}

* The usual intake of iron at 6 months was significantly different for males and females $(P<0.05)$. The estimated prevalence of inadequate intake is $4.1 \%$ for males and $16.0 \%$ for females.

†The usual intake of iron at 9 months was significantly different for males and females $(P<0.05)$. The estimated prevalence of inadequate intake is $13.6 \%$ for males and $29.6 \%$ for females.

$\ddagger$ The usual intake of zinc at 18 months was significantly different for males and females $(P<0.05)$. The estimated prevalence of inadequate intake is $61.3 \%$ for males and $74.9 \%$ for females.

$\S$ The usual intake of calcium at 24 months was significantly different for males and females $(P<0.05)$. The estimated prevalence of inadequate intake is $16.4 \%$ for males and $20.9 \%$ for females. 
months. In contrast, the average breast-fed reference newborn receives only 0.38 to $0.75 \mu \mathrm{g}$ of cholecalciferol per day from $750 \mathrm{ml}$ of human milk ${ }^{27,28}$. Therefore, the inclusion of breast-fed infants decreases the mean dietary intake of vitamin D for the sample, particularly at the youngest ages. The deficit we observed occurred later in infancy when the children were weaned off nutrient-rich infant formula. This hypothesis agrees with the findings of others who reported vitamin D inadequacy in the diets of toddlers and pre-school children to the age of five $\mathrm{e}^{10,11}$. Since the prevalence of inadequate calcium intake was low compared with that of vitamin $\mathrm{D}$, it is possible that these infants were not consuming adequate amounts of cow's milk. While there are alternative food sources of calcium such as cheese, broccoli and yoghurt, fortified milk is the only substantial food source of vitamin $\mathrm{D}^{16}$.

In contrast to previous studies that reported mean zinc intakes below the RDA in early infancy ${ }^{14,29}$, we found low zinc intake to be more problematic during the second year of life (12 to 24 months). Purvis and Bartholmey reported that slightly more than a quarter $(27 \%)$ of the 2 - to 12 -month-old infants in their survey had zinc intakes less than two-thirds of the RDA ${ }^{30}$. In our study, less than $20 \%$ of the younger infants were at risk for inadequate zinc intake while more than half of the 12- and 18-month-old infants were at risk for inadequate dietary intake of zinc. In fact, the prevalence of inadequate zinc intake was low in early infancy (12-19\%), but remarkably high at 12 months (72\%) and beyond (54-67\%). These findings are consistent with a nation-wide survey from 1989 to 1991 , which found mean zinc intakes at $62 \%$ of the RDA for 1 and 2-year-old infants ${ }^{31}$.

Several nation-wide surveys have indicated that iron intake is problematic for both infants and toddlers. Martinez and Ryan reported that iron was the nutrient most often consumed in amounts less than the RDA in their survey of infants 1 week to 12 months old, and also indicated that several other surveys of nutrient intake have shown that many infants receive low amounts of iron ${ }^{5}$. Johnson et al. reported that the mean intake of iron among 1 to 3 year olds was only $45 \%$ of the $\mathrm{RDA}^{3}$. Sanjur et al. found one-third (34\%) of their sample of 1 to 2 year olds to have iron intakes less than $67 \%$ of the $\mathrm{RDA}^{13}$; in a later cross-sectional study of infants aged 5 to 37 months, they reported that $48 \%$ of infants had an iron intake below twothirds of the RDA ${ }^{12}$.

Similar to vitamin D and zinc, we found iron intake to be more of a problem for the infants in our sample at the older ages. At 12 and 18 months, more than $40 \%$ of the sample was at risk for inadequate iron intake. At 24 months, when the group mean intake was well above the RDA, one-quarter of the infants were still estimated to have an inadequate intake of iron. Skinner et al. did not find iron intake to be a problem in their sample of infants aged 2 to 24 months from middle- to high-income families ${ }^{14}$. These conflicting findings suggest that intake of iron may be more influenced by socio-economic status than the other nutrients we examined.

Although the infants in our sample almost always consumed a sufficient number of calories, their diets were not necessarily optimal. Protein consumption was exceptionally high in the sample. This finding is in agreement with other studies in which mean protein intakes were found to be more than double the RDA ${ }^{5,12-14}$. Large-scale nutrition surveys have also reported high protein intakes ${ }^{1,5}$, which suggest that our finding for infants and toddlers from low-income families is part of a national trend. The results for energy, protein, calcium, iron and zinc intakes were comparable to those from nation-wide dietary surveys of more diverse populations ${ }^{1-4,32}$. Vitamin D has not been evaluated on the national level and, with the exception of Skinner et al. ${ }^{14}$, no other studies in the United States have reported vitamin $\mathrm{D}$ intakes for this age group.

\section{Strengths and limitations}

The dietary data for this study were collected by 24-hour recall, in which the mother or primary caretaker was the respondent. It has been demonstrated that, for groups of children, a 24-hour recall provides mean intakes for most nutrients comparable to both 2-day and 7-day food records ${ }^{12,33}$. The use of these data to estimate the group intake distribution is well established and is considered both accurate and reliable $1,2,11,14,22,23$.

The interviews were conducted on different days of the week as well as throughout the year. The 24-hour recalls captured dietary intake for weekdays (Monday to Thursday) as well as one weekend day (Sunday). The follow-up period spanned several years and data were collected during all twelve months of the year. Therefore, any dayof-the-week or seasonal bias is unlikely.

Our sample size provided a large number of observations at each age. The longitudinal design of the study allowed for repeated measurements of dietary intake within the same sample, enabling us to describe intake trends within a group of infants over two years. This is a substantially longer follow-up than many previous studies have achieved and is important because it spans a critical period of growth, development and dietary transition.

As the infants begin to eat more table foods and develop likes and dislikes, there is more opportunity for variety in the diet. In older infants, day-to-day variation in diet is likely to increase, resulting in greater intra-infant as well as the inter-infant variability. This is a potential concern when the 24-hour recall is used to estimate intake. Since our follow-up extended through the second year of life, it is possible that our mean intake estimates are more accurate at the younger ages than at 12, 18 and 24 months.

We did not to attempt to quantify the nutrient value contained in breast milk. We chose to exclude infant diets containing breast milk and only analysed diets consisting of infant foods, formulas and/or table foods. Other studies 
have applied published values for breast milk to estimated volumes in order to approximate the nutrients consumed. Therefore, we are unable to directly compare our results with others who employed these estimation techniques to describe a sample containing both breast-fed and nonbreast-fed infants.

In general, the prevalence of dietary supplement use in this sample was comparable to national data ${ }^{34}$. Supplement use in our sample from 3 to 9 months of age ranged from $18 \%$ to $29 \%$, while the national prevalence for infants aged 2 to 11 months is $28 \%$. The prevalence of supplement use among 12 to 24 month olds in our sample was slightly lower than the national average. One- to 2 -year-old infants in our sample had reported supplement usage ranging from $32 \%$ to $40 \%$ while the national prevalence for 1 to 2 year olds is $43 \%$. The national prevalences for non-Hispanic black infants are slightly lower (20\% for 2 to 11 months and 33\% for 1 to 2 years). This is noteworthy because the majority of the infants in our sample $(55 \%)$ were non-white and non-Hispanic. Since dietary intake from food sources was the focus of this paper, the nutrient content of vitamin and mineral supplements was not considered. When determining the overall adequacy of nutrient intake among children, more precise estimates may be obtained by considering vitamin and mineral intakes from supplements as well as those from food sources.

The sample in our study was restricted to healthy infants from families of lower socio-economic status, infants who lived in a north-eastern state, and infants whose mothers were willing to participate in several interviews conducted at a paediatric clinic over a 2 -year period. The women enrolled in our study sought prenatal care in the first or second trimester of pregnancy. It is possible that women who seek early prenatal care may also engage in other health behaviours such as eating nutritious food and feeding their children similarly. Since these mothers may have an overall healthier lifestyle than women who did not seek prenatal care, our results can only describe infants born to low-income women who receive early prenatal care.

\section{Conclusion}

Although the diets of these children appeared generally adequate in early infancy, they seemed to deteriorate as the infants grew older. Protein consumption, while always in excess of the RDA, became extremely high during the second year of life (12 to 24 months). Low vitamin D, zinc and iron intakes also appeared to be problematic for a large number of infants in this sample. The transition period from infancy to toddlerhood ( 9 to 18 months) is perhaps the most critical in terms of intervention. Dietetics practitioners and health educators need to encourage mothers to include additional foods containing vitamin D, zinc and iron (such as whole milk and fortified cereals) in their children's diets as they are weaned from infant formula.

\section{References}

1 McDowell MA, Briefel RR, Alaimo K, Bischof AM, Caughman CR, Carroll MD, et al. Energy and macronutrient intakes of persons ages 2 months and over in the United States: Third National Health and Nutrition Examination Survey, Phase 1, 1988-91. Advance Data from Vital and Health Statistics, No. 255. Hyattsville, MD: National Center for Health Statistics 1994.

2 Alaimo K, McDowell MA, Briefel RR, Bischof AM, Caughman CR, Loria CM, et al. Dietary intake of vitamins, minerals, and fiber of persons ages 2 months and over in the United States: Third National Health and Nutrition Examination Survey, Phase 1, 1988-91. Advance Data from Vital and Health Statistics, No. 258. Hyattsville, MD: National Center for Health Statistics 1994.

3 Johnson RK, Guthrie H, Smiciklas-Wright H, Wang MQ. Characterizing nutrient intakes of children by sociodemographic factors. Public Health Rep. 1994; 109: 414-20.

4 Ernst JA, Brady MS, Rickard KA. Food and nutrient intake of 6- to 12-month-old infants fed formula or cow milk: a summary of four national surveys. J. Pediatr. 1990; 117: S86-S100.

5 Martinez GA, Ryan AS. Nutrient intake in the United States during the first 12 months of life. J. Am. Diet. Assoc. 1985; 85: 826-30.

6 Skinner JD, Carruth BR, Houck K, Moran J III, Coletta F, Cotter $\mathrm{R}$, et al. Transitions in infant feeding during the first year of life. J. Am. Coll. Nutr. 1997; 16: 209-15.

7 Parraga IM, Weber MA, Engel A, Reeb KG, Lerner E. Feeding patterns of urban black infants. J. Am. Diet. Assoc. 1988; 88: $796-800$

8 Kokinos M, Dewey KG. Infant feeding practices of migrant Mexican-American families in Northern California. Ecol. Food Nutr. 1986; 18: 209-20.

9 Brogan BD, Fox HM. Infant feeding practices of low- and middle-income families in Nebraska. J. Am. Diet. Assoc. 1984; 84: 560-3.

10 Skinner JD, Carruth BR, Houck KS, Bounds W, Morris M, Cox $\mathrm{DR}$, et al. Longitudinal study of nutrient and food intakes of white preschool children aged 24 to 60 months. J. Am. Diet. Assoc. 1999; 99: 1514-21.

11 Zive MM, Taras HL, Broyles SL, Frank-Spohrer GC, Nader PR. Vitamin and mineral intakes of Anglo-American and Mexican-American preschoolers. J. Am. Diet. Assoc. 1995; 95: 329-35.

12 Sanjur D, Oyarzun M, Furumoto R, Parpia B, Bueso C, Rodriguez L. Dietary patterns, nutrient intakes, and nutritional anthropometry of urban Puerto Rican toddlers. J. Nutr. Educ. 1994; 26: 171-9.

13 Sanjur D, Garcia A, Aguilar R, Furumoto R, Mort M. Dietary patterns and nutrient intakes of toddlers from low-income families in Denver, Colorado. J. Am. Diet. Assoc. 1990; 90: 823-9.

14 Skinner JD, Carruth BR, Houck KS, Coletta F, Cotter R, Ott D, et al. Longitudinal study of nutrient and food intakes of infants aged 2 to 24 months. J. Am. Diet. Assoc. 1997; 97: 496-504

15 Centers for Disease Control. Preventing Lead Poisoning in Young Children. Hyattsville, MD: US Department of Health and Human Services, 1991.

16 Food and Nutrition Board. Recommended Dietary Allowances, 10th ed. Washington, DC: National Academy Press, 1989.

17 Schell LM, Stark AD, Gomez MI, Grattan WA. Blood lead level, by year and season, among poor pregnant women. Arch. Environ. Health 1997; 52: 286-91. 
18 Schell LM, Ravenscroft J, Czerwinski SA, Stark AD, Grattan WA, Gordon M. Social support and adverse pregnancy outcome in a high-risk population. J. Public Health Manag. Pract. 1997; 3: 13-26.

19 First DataBank/N-Squared Computing. Nutritionist IV Diet Analysis for Windows, Version 4.1. San Bruno, CA: First DataBank/N-Squared Computing, 1995.

20 Borland, Inc. Visual dBase, Version 5.5. Scotts Valley, CA: Borland, Inc., 1995.

21 SAS Institute, Inc. The SAS System for Windows, Release 6.12. Cary, NC: SAS Institute, Inc., 1996.

22 National Research Council. Nutrient Adequacy: Assessment Using Food Consumption Surveys. Washington, DC: National Academy Press, 1986.

23 Institute of Medicine. Dietary Reference Intakes: Applications in Dietary Assessment. Washington, DC: National Academy Press, 2001.

24 Centers for Disease Control. CDC Growth Charts: United States [Online]. Available at http://www.cdc.gov/nchs/ about/major/nhanes/growthcharts/datafiles.htm. US Department of Health and Human Services, 2001.

25 Cid-Ruzafa J, Caulfield L, Barron Y, West S. Nutrient intakes and adequacy among an older population on the Eastern Shore of Maryland: The Salisbury Eye Evaluation. J. Am. Diet. Assoc. 1999; 99: 564-71.

26 Fomon SJ. Infant Nutrition, 2nd ed. Philadelphia, PA: WB Saunders, 1974.
27 American Academy of Pediatrics. Composition of human milk; normative data. In: Pediatric Nutrition Handbook. Elk Grove Village, IL: American Academy of Pediatrics, 1985; 363-8.

28 Reeve LE, Chesney RW, DeLuca HF. Vitamin D of human milk: identification of biologically active forms. Am. J. Clin. Nutr. 1982; 36: 122-6.

29 Michaelsen KF, Samuelson G, Graham TW, Lonnerdal B. Zinc intake, zinc status and growth in a longitudinal study of healthy Danish infants. Acta Paediatr. 1994; 83: 1115-21.

30 Purvis GA, Bartholmey SJ. Infant feeding practices: commercially prepared baby foods. In: Tsang RC, Nichols BF, eds. Nutrition During Infancy. Philadelphia, PA: Hanley \& Belfus, 1988; 399-417.

31 Tippett KS, Mickle SJ, Goldman JD, Sykes KE, Cook DA, Wilson JW, et al. Food and Nutrient Intakes by Individuals in the United States, 1 Day, 1989-1991. Washington, DC: US Department of Agriculture, 1995.

32 Rose D, Habicht JP, Devaney B. Household participation in the food stamp and WIC programs increases the nutrient intakes of preschool children. J. Nutr. 1998; 128: 548-55.

33 Persson LA, Carlgren G. Measuring children's diets: evaluation of dietary assessment techniques in infancy and childhood. Int. J. Epidemiol. 1984; 13: 506-17.

34 Ervin R, Wright J, Kennedy-Stephenson J. Use of Dietary Supplements in the United States, 1988-94. Hyattsville, MD: US Department of Health and Human Services, 1999. 